\title{
Conhecimento dos consumidores e eficiência dos métodos de lavagem e desinfecção de alface (Lactuca sativa) comercializada em supermercados em uma cidade do sul do Brasil
}

\section{Consumer knowledge and efficiency of laundry and disinfection methods of lettuce (Lactuca sativa) commercialized in supermarkets in a southern city of Brazil}

\author{
Eliandra Mirlei Rossi ${ }^{1 *}$ (D), Raquel Rech Guzela ${ }^{1}$, Marília Kochhann ${ }^{1}$ \\ Larissa Kochhann Menezes ${ }^{1}$, Jessica Fernanda Barreto Honorato ${ }^{1}$ \\ ${ }^{1}$ Universidade do Oeste de Santa Catarina (UNOESC), Departamento de Ciências da Vida e Saúde, São Miguel do \\ Oeste/SC - Brasil
}

*Corresponding Author: Eliandra Mirlei Rossi, Universidade do Oeste de Santa Catarina (UNOESC),

Departamento de Ciências da Vida e Saúde, Rua Oiapoc, 211, Bairro Agostini, CEP: 89900-000, São Miguel do

Oeste/SC - Brasil, e-mail: eliandra_bio@yahoo.com.br

Cite as: Rossi, E. M., Guzela, R. R., Kochhann, M., Menezes, L. K., \& Honorato, J. F. B. (2020). Consumer knowledge and efficiency of laundry and disinfection methods of lettuce (Lactuca sativa) commercialized in supermarkets in a southern city of Brazil. Brazilian Journal of Food Technology, 23, e2019245.

https://doi.org/10.1590/1981-6723.24519

\begin{abstract}
Resumo
A alface é um vegetal mundialmente consumido. Porém, quando mal higienizada pode ser a causa de doenças transmitidas por alimentos. Esse trabalho teve como objetivo verificar o conhecimento dos manipuladores referente à lavagem e desinfecção de vegetais e avaliar a eficiência de diferentes processos de lavagem e desinfecção de alface (Lactuca sativa) comercializada em supermercados. Foi aplicado um questionário aos consumidores para conhecer as práticas de lavagem e desinfecção dos vegetais. Foram adquiridas 100 amostras de alfaces em diferentes supermercados. Para avaliar a qualidade microbiológica das alfaces, foram usados: alface sem tratamento (T0); lavagem com água tratada corrente (T1); imersão em água tratada por 30 minutos (T2); imersão em hipoclorito de sódio a 200 ppm por 15 minutos (T3); e 30 minutos (T4); imersão em solução de vinagre a 2\% (T5); imersão em solução de vinagre a 20\% (T6); imersão em hipoclorito de sódio a 50 ppm por 30 minutos (T7); e 15 minutos (T8). Após a realização dos tratamentos, foi realizada contagem total de bactérias heterotróficas e coliformes termotolerantes. A contagem média de bactérias heterotróficas encontradas antes da higienização (TO) foi de $5,54 \log$ UFC/g. A maioria dos consumidores afirmou que faz a lavagem das alfaces apenas com água; somente 7,50\% fazem a desinfecção; e 56,3\% afirmam não ter conhecimento da maneira correta da higienização dos vegetais. Todos os métodos utilizados foram capazes de reduzir as contagens de bactérias heterotróficas, sendo que as melhores reduções foram apresentadas respectivamente pelos tratamentos T4 (2,27 log UFC/g) e T3 (2,09 log UFC/g). Nenhuma das amostras apresentou contaminação por coliformes antes e depois da higienização. Esses resultados permitem concluir que métodos de lavagem e desinfecção de alfaces são necessários para reduzir
\end{abstract}


a contaminação microbiana nesse alimento antes do consumo e que se torna necessário orientar os consumidores da importância dessa prática.

Palavras-chave: Vegetal folhoso; Bactérias heterotróficas; Coliformes; Contaminação; Higienização; Manipulador.

\begin{abstract}
Lettuce is a vegetable most consumed worldwide. However, when not properly sanitized, it can cause various foodborne illnesses. Thus, this research aimed to verify the knowledge of handlers regarding the washing and disinfection of vegetables, as well as to evaluate the efficiency of different processes of washing and disinfection of lettuce (Lactuca sativa) sold in supermarkets. A questionnaire was applied to consumers to know the practices used for washing and disinfecting vegetables. After, 100 samples of lettuce were purchased in different supermarkets. To evaluate the microbiological quality of lettuces we used: lettuce without treatment (T0); washing with running tap water (T1); immersion in treated water for 30 minutes (T2); immersion in sodium hypochlorite at $200 \mathrm{ppm}$ for 15 minutes (T3); and 30 minutes (T4); immersion in 2\% vinegar solution (T5); immersion in 20\% vinegar solution (T6); immersion in sodium hypochlorite at 50 ppm for 30 minutes (T7); and 15 minutes (T8). After the treatments, we performed a total count of heterotrophic bacteria and thermotolerant coliforms. The mean heterotrophic bacteria count found before sanitation (T0) was $5.54 \mathrm{log}$ UFC/g. Most consumers say they only wash lettuce with water and only $7.50 \%$ disinfect. In $56.3 \%$, the consumers are not aware of the correct way to clean vegetables. All methods used were able to reduce heterotrophic bacteria counts and the best reductions were presented respectively by treatments T4 (2.27 log UFC/g) and T3 (2.09 log UFC/g). None of the samples showed thermotolerant coliforms contamination before and after cleaning. These results allow us to conclude that lettuce washing and disinfection methods are necessary to reduce microbial contamination in this food before consumption and that it is necessary to guide consumers of the importance of this practice.
\end{abstract}

Keywords: Leafy vegetable; Heterotrophic bacteria; Coliforms; Contamination; Sanitation; Handlers.

\title{
1 Introdução
}

Dentre os vegetais folhosos, o mais consumido no mundo é a alface (Lactuca sativa L., cichoraceae), pois é um vegetal de fácil aquisição, que se destaca por ser uma hortaliça de baixo custo e alta aceitação (Viacava et al., 2018).

As hortaliças fazem parte da alimentação da maioria da população mundial, por serem de baixo valor calórico e ricas em sais de cálcio, ferro e vitaminas (Viacava et al., 2018; Botella et al., 2018; Birmpa et al., 2018). Apesar de apresentar todos esses benefícios aos consumidores, de Andrade Bernal Fagiani et al. (2017) destacam que esse vegetal folhoso quando contaminado pode causar diferentes doenças transmitidas por alimentos (DTA).

No Brasil, o Sistema de Vigilância em Saúde de 2000 a 2017 relatou 12.660 surtos de DTA e, desses, os vegetais foram responsáveis por 1,09\% dos casos (Brasil, 2018). Elias et al. (2018) relataram que, entre 2008 e 2014, no Brasil, foram relacionados à produção de alface trinta surtos de DTA, o que resultou em 2926 doentes e 347 hospitalizações.

Diversos estudos (Elias et al., 2018; Banach et al., 2018; Maïworé et al., 2017; Bencardino et al., 2018) já demonstram que vegetais podem ser responsáveis pelos surtos de DTA e que muitos fatores podem afetar a segurança de um alimento, por exemplo, a falta de práticas higiênicas sanitárias apropriadas. Por essa razão, a higienização correta das hortaliças é essencial para garantir a qualidade dos vegetais consumidos in natura.

Desse modo, observa-se a necessidade de realizar estudos que investiguem a qualidade microbiológica dos vegetais folhosos, uma vez que na maioria das vezes os consumidores fazem a lavagem somente com água antes do consumo. Esse método pode não eliminar os patógenos e consequentemente aumentar os riscos de aquisição de DTA. 
Vários estudos têm demonstrado (Bencardino et al., 2018; Osaili et al., 2018) a eficácia de diversos sanitizantes utilizados para reduzir a contaminação microbiológica de frutas e verduras, como o hipoclorito de sódio, ácido acético, ácido ascórbico e outras combinações.

O hipoclorito de sódio é um dos principais sanitizantes utilizados para a desinfecção de alimentos, pois normalmente apresenta baixo custo, ação rápida e eficiente. De acordo com Banach et al. (2018) e Brasil (2018), é recomendada a imersão das frutas e verduras por 15 a 30 minutos em soluções com 50 a 200 ppm de hipoclorito de sódio (Banach et al., 2018; Brasil, 2018).

Assim, o objetivo deste trabalho foi conhecer as práticas usadas por consumidores para lavar os vegetais antes do consumo, bem como avaliar a eficiência de diferentes métodos de lavagem e desinfecção de alface (Lactuca sativa) comercializada em supermercados de uma cidade do sul do Brasil.

\section{Materiais e métodos}

\subsection{Investigação do conhecimento e métodos usados por consumidores de alface}

Para avaliar o conhecimento dos consumidores de alface em relação à manipulação e aos métodos de lavagem e desinfecção desse vegetal folhoso, foram entrevistados 240 consumidores residentes em uma cidade do sul do Brasil.

Para isso, foi usado um questionário (Tabela 1) elaborado na ferramenta "formulários google" com questões de múltipla escolha que foi enviado por e-mail para os consumidores participantes deste estudo.

Tabela 1. Questionário aplicado aos consumidores de hortaliças in natura.

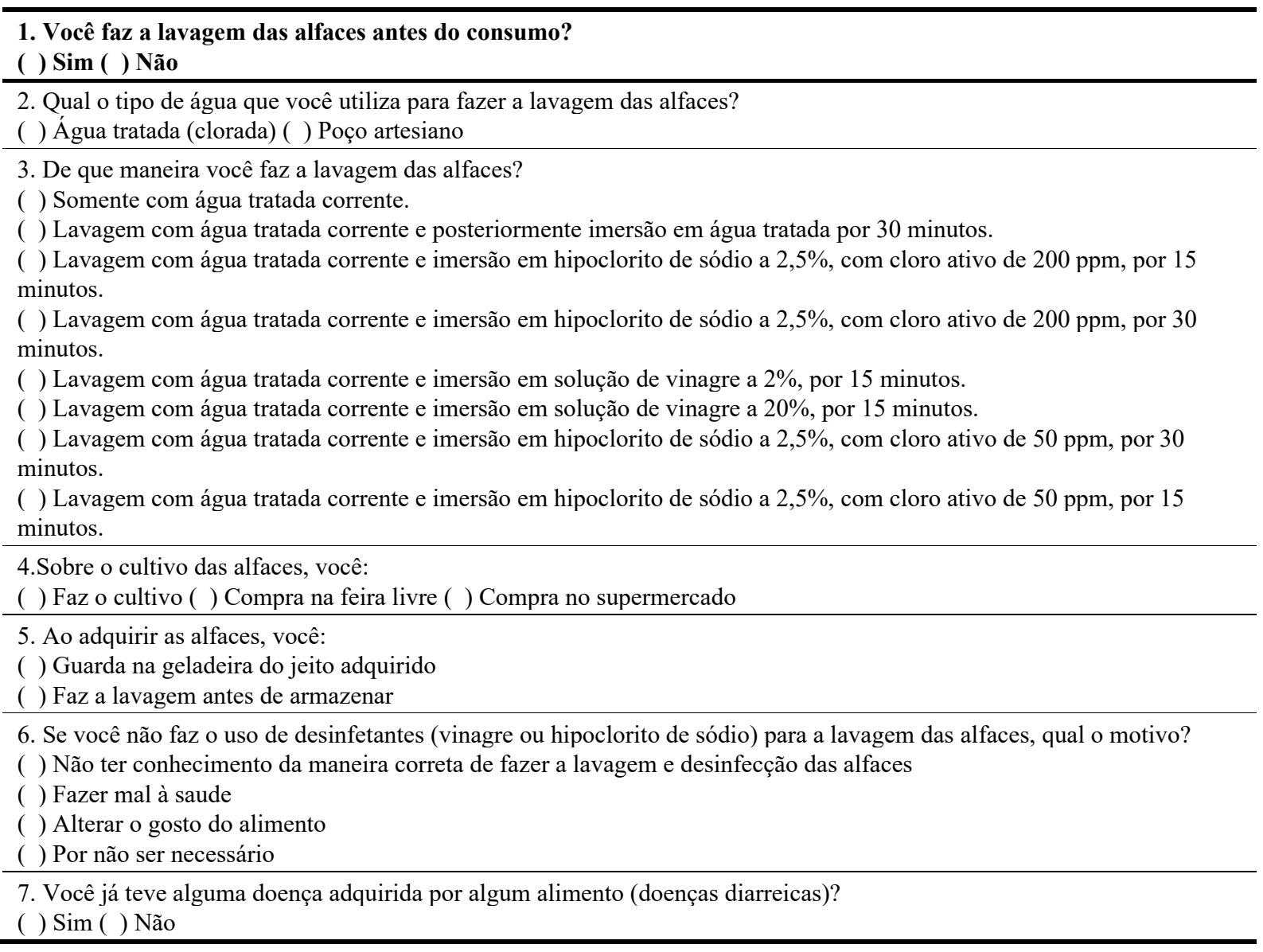




\section{Eficiência dos métodos de lavagem e desinfecção}

\subsection{Amostras}

O estudo foi realizado no período de agosto de 2017 a agosto de 2018 e as coletas de alfaces foram realizadas em dez supermercados, sendo armazenadas a $4{ }^{\circ} \mathrm{C}$ no máximo por 24 horas antes dos experimentos.

\subsection{Análises microbiológicas}

Os procedimentos metodológicos foram realizados no Laboratório de Microbiologia da Universidade do Oeste de Santa Catarina - UNOESC, campus de São Miguel do Oeste-SC.

Inicialmente $500 \mathrm{~g}$ de folhas oriundas de pelo menos cinco pés de alface foram colocadas em uma bacia plástica estéril. Em seguida, aleatoriamente, foram escolhidas $25 \mathrm{~g}$ dessa amostragem e submetidas a análises microbiológicas (contagem de coliformes termotolerantes e de bactérias heterotróficas).

As folhas das alfaces restantes foram submetidas a métodos de lavagem e desinfecção (descritos no item 3.3) e novamente submetidas a análises microbiológicas (contagem de coliformes termotolerantes e de bactérias heterotróficas).

\subsection{Métodos de lavagem e desinfecção}

Para avaliar a eficiência de diferentes métodos de lavagem e desinfecção, as alfaces foram submetidas a sete tratamentos.

Foram utilizados $25 \mathrm{~g}$ de alfaces para cada tratamento descrito abaixo e estes foram conduzidos em dez repetições em dias diferentes.

T0 - Controle: alface sem tratamento.

T1 - Lavagem com água tratada corrente.

T2 - Lavagem com água tratada corrente e posteriormente imersão em água tratada por 30 minutos.

T3 - Lavagem com água tratada corrente e posteriormente imersão em hipoclorito de sódio a 2,5\%, com cloro ativo de $200 \mathrm{ppm}$, por 15 minutos.

T4 - Lavagem com água tratada corrente e posteriormente imersão em hipoclorito de sódio a 2,5\%, com cloro ativo de $200 \mathrm{ppm}$, por 30 minutos.

T5 - Lavagem com água tratada corrente e posteriormente imersão em solução de vinagre a $2 \%$, por 15 minutos.

T6 - Lavagem com água tratada corrente e posteriormente imersão em solução de vinagre a $20 \%$, por 15 minutos.

T7 - Lavagem com água tratada corrente e posteriormente imersão em hipoclorito de sódio a 2,5\%, com cloro ativo de $50 \mathrm{ppm}$, por 30 minutos.

T8 - Lavagem com água tratada corrente e posteriormente imersão em hipoclorito de sódio a 2,5\%, com cloro ativo de $50 \mathrm{ppm}$, por 15 minutos.

Nos tratamentos de T2 a T8, as folhas de alface foram novamente enxaguadas com água tratada corrente após terem sido submetidas aos tratamentos. 


\subsection{Contagem de bactérias heterotróficas e contagem de coliformes termotolerantes}

A contagem total de bactérias heterotróficas e de coliformes termotolerantes foi realizada de acordo com a metodologia do Ministério da Agricultura, Pecuária e Abastecimento (MAPA), conforme descrito na Instrução Normativa ${ }^{\circ}$ 62, de 26 de agosto de 2003 (Brasil, 2003).

Para cada tratamento, foram pesadas $25 \mathrm{~g}$ de alface e acrescidas de $225 \mathrm{~mL}$ de Água Peptonada $0,1 \% \mathrm{e}$ homogeneizadas em "Stomacher" por 60 segundos.

A contagem de bactérias heterotróficas foi realizada através da técnica de Pour-Plate, onde foi semeado $1 \mathrm{~mL}$ da amostra previamente diluída e homogeneizada em "Stomacher" por 60 segundos em placas estéreis, nas quais foi adicionado ágar Padrão para Contagem (PCA) e posteriormente incubadas a $36 \pm 1{ }^{\circ} \mathrm{C}$ por 48 horas.

Para a contagem de coliformes termotolerantes, foi utilizada a técnica de Pour-Plate sobrecamada, onde foi semeado $1 \mathrm{~mL}$ de diferentes diluições da amostra previamente diluída e homogeneizada em placas estéreis, nas quais foi adicionado ágar Bile Vermelho Violeta (VRB) e posteriormente incubadas a $36 \pm 1{ }^{\circ} \mathrm{C}$. Após 24 horas, foi realizada a contagem das colônias características (rosas com halo), em seguida, as colônias características foram transferidas para caldo EC, e este foi incubado a $45 \pm 0,2{ }^{\circ} \mathrm{C}$, por 24 a 48 horas.

\section{Redução microbiana}

Para avaliar a redução da contagem dos microrganismos teste para cada tratamento utilizado no processo de lavagem e desinfecção, utilizou-se o seguinte cálculo (Equação 1):

$$
R=\left(U F C / g \text { no } T_{0}\right)-\left(U F C / g \text { no } T_{n}\right)
$$

onde R é o resultado da contagem de cada grupo de microrganismo (coliformes termotolerantes, contagem total de bactérias heterotróficas), $\mathrm{T}_{0}$ é o controle e $\mathrm{T}_{\mathrm{n}}$ é cada tratamento $\left(\mathrm{T}_{1}\right.$ ao $\left.\mathrm{T}_{8}\right)$.

A redução microbiana foi calculada separadamente para cada grupo de microrganismo testado.

\section{Análise estatística}

Para avaliar a eficácia dos tratamentos aplicados nas folhas de alface, foram utilizados os valores das reduções da contagem dos grupos de microrganismos para cada método utilizado e aplicado o teste de ANOVA, usando o nível de significância de $p<0,05$ para cada teste e o programa utilizado foi o Assistat Versão 7.7 beta 2013.

\section{Resultados e discussão}

Os resultados demonstraram que todos $(100 \%)$ os consumidores relataram que fazem a lavagem das alfaces antes do consumo. Desses, 72,5\% utilizam água tratada (clorada) na lavagem das alfaces.

A maioria $(49,4 \%)$ dos consumidores relatou que adquire alface nos supermercados e 52,1\% armazenam na geladeira sem qualquer tipo de higienização (Figura 1). 


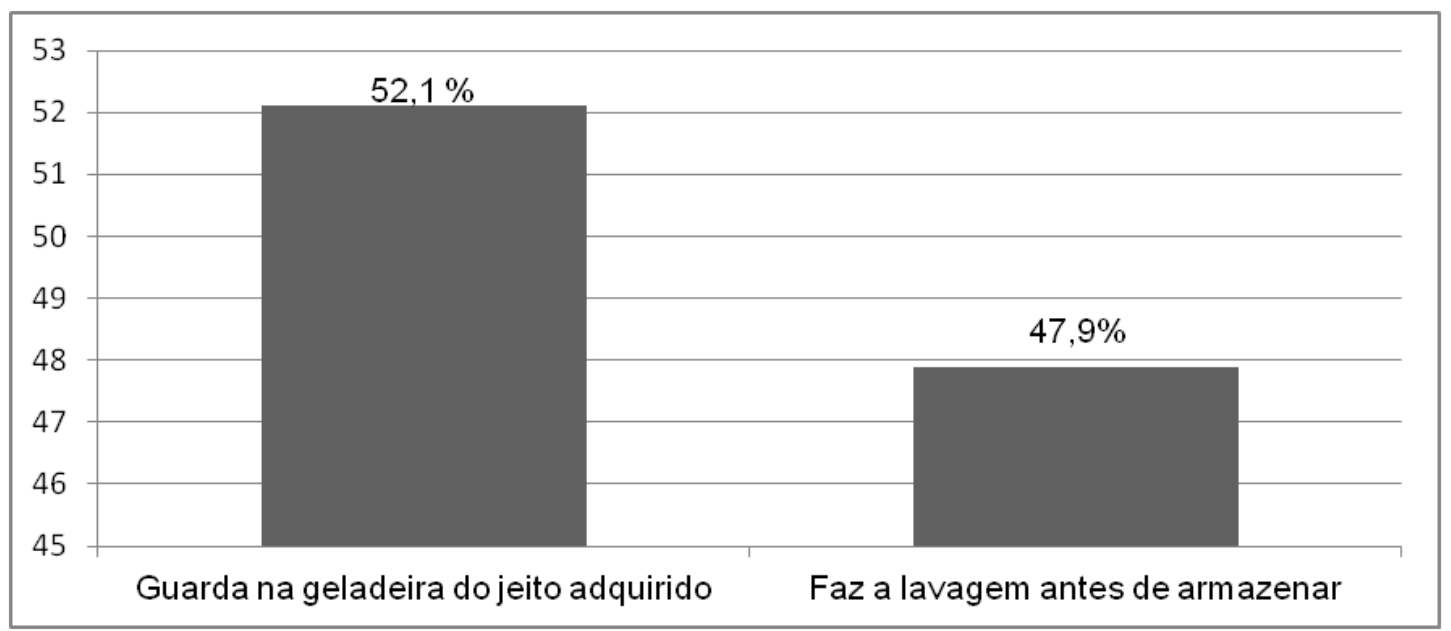

Figura 1. Maneiras de aquisição e de armazenamento das alfaces realizadas pelos consumidores entrevistados.

Além disso, verificamos que a maioria $(92,6 \%)$ dos consumidores de alfaces não realiza a higienização correta desse alimento. Desses, $72,5 \%$ fazem a lavagem somente com água tratada, 5,4\% dos entrevistados utilizam vinagre como um agente desinfetante e apenas 7,5\% realizam a higienização recomendada pela Agência Nacional de Vigilância Sanitária (2005) (Tabela 2) .

Tabela 2. Tipo de higienização usado pelos consumidores entrevistados antes de consumir alface.

\begin{tabular}{lc}
\hline \multicolumn{1}{c}{ Tratamento } & $\begin{array}{c}\text { Número de } \\
\text { consumidores }\end{array}$ \\
\hline T1 - Lavagem com água tratada corrente. & $174(72,50 \%)$ \\
\hline T2 - Lavagem com água tratada corrente e posteriormente imersão em água tratada por 30 minutos. & $29(12,10 \%)$ \\
\hline $\begin{array}{l}\text { T3 - Lavagem com água tratada corrente e posteriormente imersão em hipoclorito de sódio a 2,5\%, } \\
\text { com cloro ativo de 200 ppm, por 15 minutos seguido de enxague com água potável. }\end{array}$ & $17(7,10 \%)$ \\
\hline $\begin{array}{l}\text { T4 - Lavagem com água tratada corrente e posteriormente imersão em hipoclorito de sódio a 2,5\%, } \\
\text { com cloro ativo de 200 ppm, por 30 minutos seguido de enxague com água potável. }\end{array}$ & $1(0,40 \%)$ \\
\hline T5 - Lavagem com água tratada corrente e posteriormente imersão em solução de vinagre a 2\%, por & $1(0,40 \%)$ \\
\hline 15 minutos seguido de enxague com água potável. & $5(2,10 \%)$ \\
\hline $\begin{array}{l}\text { T6 - Lavagem com água tratada corrente e posteriormente imersão em solução de vinagre a 20\%, } \\
\text { por 15 minutos seguido de enxague com água potável. }\end{array}$ & $7(2,90 \%)$ \\
\hline $\begin{array}{l}\text { T7 - Lavagem com água tratada corrente e posteriormente imersão em hipoclorito de sódio a 2,5\%, } \\
\text { com cloro ativo de 50 ppm, por 30 minutos seguido de enxague com água potável. }\end{array}$ & $6(2,50 \%)$ \\
\hline $\begin{array}{l}\text { T8 - Lavagem com água tratada corrente e posteriormente imersão em hipoclorito de sódio a 2,5\%, } \\
\text { com cloro ativo de 50 ppm, por 15 minutos seguido de enxague com água potável. }\end{array}$ & \\
\hline
\end{tabular}

Poucos trabalhos são encontrados na literatura demonstrando as atitudes dos consumidores de alface, o que dificulta a comparação dos nossos dados, mas demonstra a importância da nossa pesquisa. Jacxsens et al. (2015) demonstraram que a maioria dos consumidores da Espanha e Bélgica também armazenam as alfaces na geladeira e a minoria ( $2 \%$ na Espanha e $1 \%$ na Bélgica) não fazem a lavagem das folhas antes do consumo.

Resultados semelhantes foram encontrados por Oliveira et al. (2012) nos manipuladores de alface dos restaurantes de Porto Alegre-RS, sendo que 39\% dos estabelecimentos lavava as alfaces com água potável e posteriormente deixava esse vegetal em imersão na água tratada. 
A legislação brasileira (Brasil, 2004) recomenda que alimentos como frutas, legumes e hortaliças devem ser higienizados (lavagem e desinfecção), tendo em vista que esses podem ser consumidos crus e, se contaminados, podem transmitir microrganismos aos consumidores.

A higienização correta elimina os microrganismos patogênicos e os parasitas e, para isso, recomenda-se a seleção, retirando as folhas, partes e unidades deterioradas, seguida de lavagem em água corrente folha a folha. Posteriormente essas devem ser imersas por 10 minutos em água clorada (200 ppm), seguido de enxague em água corrente (Brasil, 2004).

Oliveira et al. (2012) demonstraram também que a concentração e tempo de contato dos sanitizantes usados para higienização das alfaces não era controlada, o que pode alterar significativamente a eficácia do método.

Esses dados citados por Oliveira et al. (2012) são semelhantes ao nosso estudo, pois a maioria $(56,3 \%)$ dos entrevistados afirmou que não sabe como fazer essa higienização nos vegetais e, ainda, 26,1\% relataram que não acham necessário seguir todas as etapas da higienização das verduras (Figura 2).

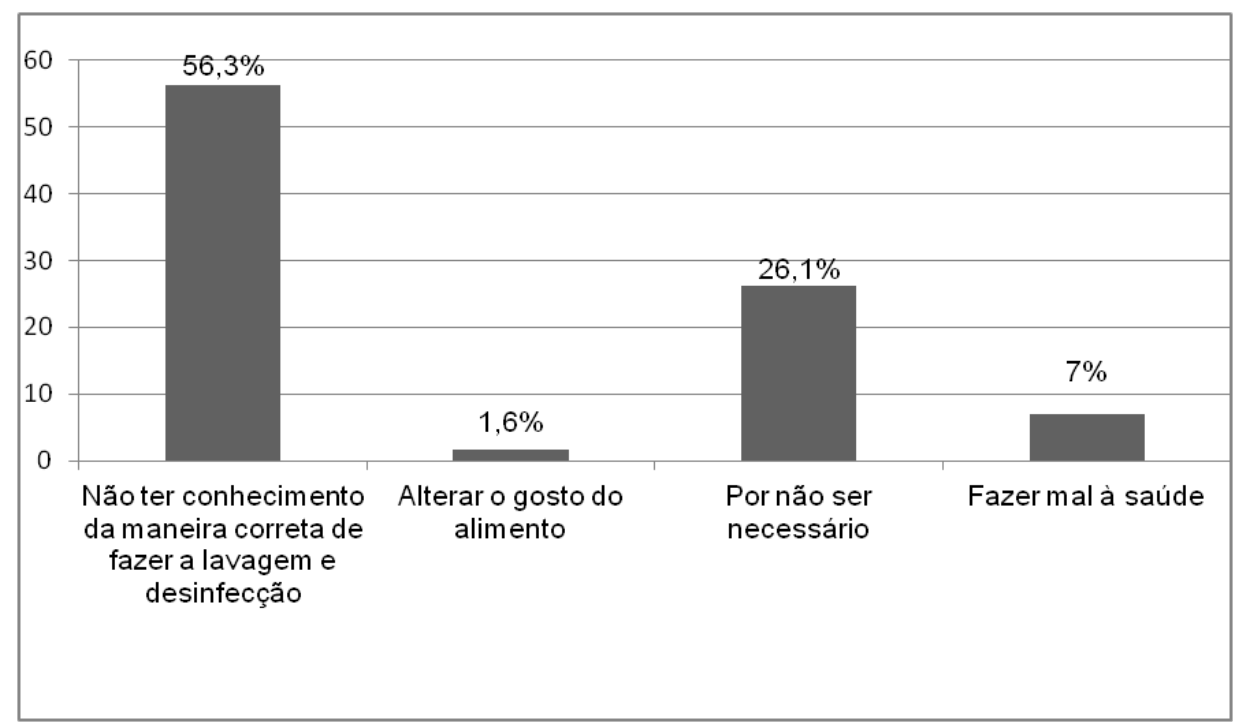

Figura 2. Motivo dos consumidores de não realizarem a desinfecção das alfaces antes do consumo.

Esses resultados podem ser explicados pelo fato de que a maioria $(54,4 \%)$ dos entrevistados nunca teve doenças relacionadas à ingestão de alfaces contaminadas. Por outro lado, torna-se necessário destacar que esses dados podem não ser verdadeiros, pois os consumidores na maioria das vezes não associam e/ou reconhecem as doenças transmitidas por alimentos.

Além disso, observa-se a necessidade da ampla divulgação das técnicas de higienização de frutas e verduras, bem como capacitação para os consumidores, tendo em vista o amplo consumo desse alimento.

Schirmer et al. (2019) demonstraram a importância da capacitação dos manipuladores em creches públicas na cidade de Cuibá -MT, pois nesses locais as alfaces apresentaram contaminação por coliformes termotolerantes e, após a orientação para as merendeiras sobre como realizar a higienização de frutas e verduras, a contaminação não foi mais encontrada.

\subsection{Contaminação das amostras de alface comercializadas em supermercados antes da higienização}

Os resultados revelaram que antes da higienização das alfaces todas as amostras apresentaram ausência $(<10 \mathrm{UFC} / \mathrm{g})$ de contaminação por coliformes termotolerantes. 
Diferentemente dos nossos resultados, Bobco et al. (2011) demonstraram que as amostras de alface in natura apresentaram contaminação por coliformes termotolerantes antes da higienização e que após todas as amostras apresentaram ausência de coliformes termotolerantes.

Esse tipo de contaminação pode ocorrer principalmente em função do cultivo desse vegetal que na maioria das vezes possui o solo ou a água de irrigação contaminada. A contaminação por coliformes indica a precária condição higiênico-sanitária do alimento, pois são microrganismos indicadores de contaminação de origem fecal, o que implica o contato do alimento com fezes humanas ou de animais (Alves et al., 2007; Ceuppens et al., 2014).

Por outro lado, nosso estudo revelou que todas as amostras apresentaram contaminação por bactérias heterotróficas. A contagem média de bactérias heterotróficas encontradas antes da higienização (T0) foi de 5,54 log UFC/g, variando de 4,36 log UFC/g a 5,83 log UFC/g.

O termo "bactérias heterotróficas" inclui todas as bactérias que usam nutrientes orgânicos para o crescimento. Estas bactérias são universalmente presentes em todos os tipos de água, alimentos, solo, vegetação e ar (Allen et al., 2004), servindo, portanto, de indicador auxiliar ao fornecer informações adicionais sobre eventuais falhas na desinfecção (Guerra et al., 2006).

Segundo Horn (2014), a principal forma de contaminação microbiológica em hortaliças dá-se, principalmente, por meio de água contaminada utilizada na irrigação artificial de hortas, por contaminação do solo com adubo orgânico, sendo que essa contaminação é um fator preocupante para a saúde pública, principalmente pela alface ser uma das hortaliças mais vendidas para consumo sem tratamento térmico.

Entretanto sua contaminação por microrganismos é muito grande quando não se tem uma manipulação adequada desde o plantio, colheita e consumidor. Por isso, todas as etapas percorridas entre o produtor e o consumo final de hortaliças devem ser conduzidas sob condições estritamente higiênicas a fim de minimizar os riscos potenciais à saúde do consumidor (James \& Ngarmsak, 2010; Holvoet et al., 2014).

\subsection{Eficiência dos métodos de lavagem e desinfecção}

Todos os métodos utilizados neste estudo foram capazes de reduzir as contagens de bactérias heterotróficas. As melhores reduções na contagem de bactérias heterotróficas foram apresentadas respectivamente pelos tratamentos T4 (2,27 log UFC/g) e T3 (2,09 log UFC/g). No entanto, nenhum dos tratamentos foi capaz de reduzir as contagens de bactérias heterotróficas em $100 \%$, pois a redução máxima nesta pesquisa foi de 2,27 log UFC/g (no T3) e a mínima foi de 1,17 log UFC/g (no T1) (Tabela 3).

Tabela 3. Redução (log UFC/g) nas contagens de bactérias heterotróficas em alface após os tratamentos.

\begin{tabular}{lcl}
\hline \multicolumn{1}{c}{$\begin{array}{c}\text { Métodos de lavagem e desinfecção de } \\
\text { alface }\end{array}$} & $\begin{array}{c}\text { Reduções nas contagens de bactérias } \\
\text { heterotróficas (log UFC/g) }\end{array}$ & Redução \\
\hline $\mathrm{T} 1$ - Água tratada & 1,17 & $21,51 \%$ \\
\hline $\mathrm{T} 2$ - Água tratada (30 min) & 1,38 & $25,37 \%$ \\
\hline $\mathrm{T} 3$ - Hipoclorito de sódio 200 ppm (15 min) & 2,09 & $38,40 \%$ \\
\hline $\mathrm{T} 4$ - Hipoclorito de sódio 200 ppm (30 min) & 2,27 & $41,73 \%$ \\
\hline $\mathrm{T} 5$ - Vinagre 2\% (15 min) & 1,38 & $25,37 \%$ \\
\hline $\mathrm{T} 6$ - Vinagre 20\% (15 min) & 1,59 & $29,23 \%$ \\
\hline $\mathrm{T} 7$ - Hipoclorito de sódio 50 ppm (15 min) & 1.45 & $26,66 \%$ \\
\hline T8 - Hipoclorito de sódio 50 ppm (30 min) & 1.43 & $26,29 \%$ \\
\hline
\end{tabular}

$\log$ UFC/g- Unidade formadora de colônia/g convertido em $\log _{10}$. O período das imersões das soluções está expresso entre parênteses ao lado de cada tratamento. 
Os resultados encontrados neste estudo demonstraram que as amostras de alface após serem submetidas aos métodos de lavagem e desinfecção apresentaram contagens médias de bactérias heterotróficas de 3,89 $\log$ UFC/g que variaram de 4,27 log UFC/g a 3,17 log UFC/g (Figura 3).

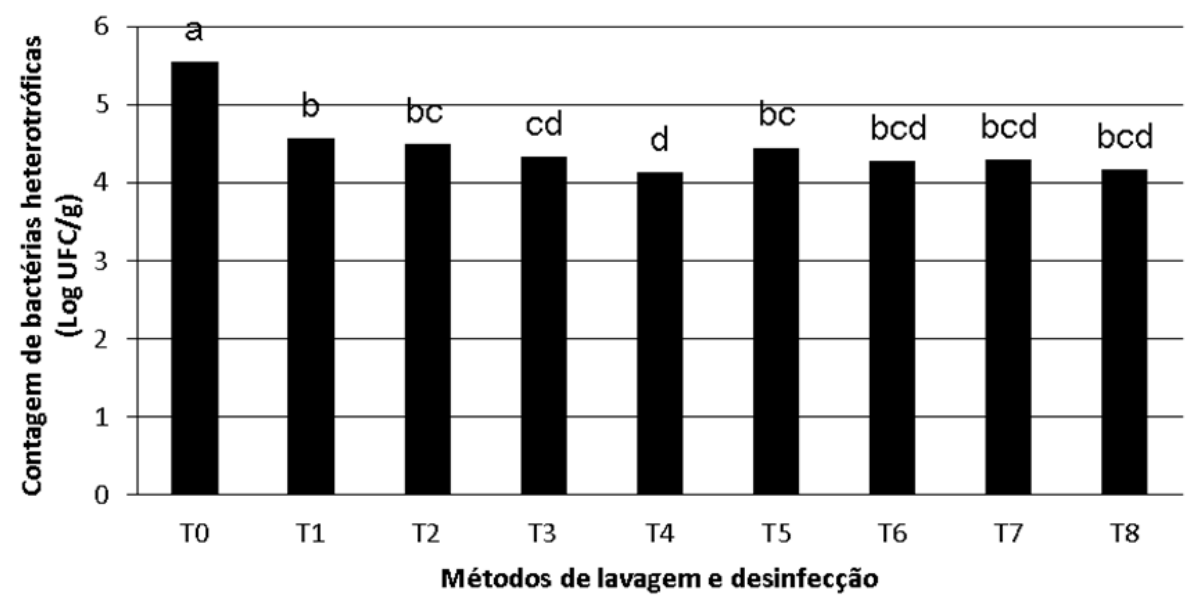

Figura 3. Contagem de bactérias heterotróficas em alface após os métodos de lavagem e desinfecção. T0- Controle: alface sem tratamento; T1- Lavagem com água tratada corrente; T2- Lavagem com água tratada corrente e posteriormente imersão em água tratada por 30 minutos; T3- Lavagem com água tratada corrente e posteriormente imersão em hipoclorito de sódio a 2,5\%, com cloro ativo de 200 ppm, por 15 minutos; T4- Lavagem com água tratada corrente e posteriormente imersão em hipoclorito de sódio a 2,5\%, com cloro ativo de 200 ppm, por 30 minutos; T5- Lavagem com água tratada corrente e posteriormente imersão em solução de vinagre a 2\%, por 15 minutos;

T6- Lavagem com água tratada corrente e posteriormente imersão em solução de vinagre $20 \%$ por 15 minutos; T7- Lavagem com água tratada corrente e posteriormente imersão em hipoclorito de sódio a $2,5 \%$, com cloro ativo de 50 ppm, por 15 minutos; T8- Lavagem com água tratada corrente e posteriormente imersão em hipoclorito de sódio a 2,5\%, com cloro ativo de $200 \mathrm{ppm}$, por 30 minutos. Letras diferentes indicam diferenças estatisticamente significantes ao nível de $5 \%$ pelo teste ANOVA.

Atualmente a legislação vigente na área de alimentos (Brasil, 2001) não possui padrões permissíveis para contagem de bactérias heterotróficas, mas sabe-se que altas contagens de bactérias podem oferecer riscos aos seus consumidores.

Segundo Jeena et al. (2006), altas concentrações de bactérias heterotróficas, representam sérios riscos para a saúde de indivíduos imunocomprometidos, pois podem conter patógenos, especialmente formas resistentes a antibióticos, embora, apesar de as bactérias heterotróficas não serem patogênicas, alguns membros desse grupo, como Legionella spp., Mycobacterium spp., Pseudomonas spp. e Aeromonas spp., podem ser patógenos oportunistas (Queiroz, 2007).

Em nosso estudo, após a higienização das alfaces, também não foram encontrados coliformes termotolerantes. Esses resultados podem ser explicados pelo fato de que antes da higienização essas mesmas alfaces não apresentavam contaminação por esse grupo de microrganismos.

Neste trabalho, observou-se que os tratamentos mais eficientes foram o T4 e T3, ou seja, com o uso de hipoclorito de sódio a 2,5\% em uma concentração de 200 ppm (Tabela 2 e Figura 3). Esses dados demonstram a importância da utilização de métodos de lavagem e desinfecção em hortaliças, pois, conforme Gündüz et al. (2010) e Oliveira et al. (2012), os tratamentos são necessários para diminuir a contaminação de vegetais. De acordo com esses autores, vários métodos têm sido utilizados, mas a desinfecção com o uso de hipoclorito de sódio ou com vinagre em diferentes concentrações é o método mais comumente usado.

O vinagre demonstrou melhor eficácia na concentração de $20 \%$ (T6) com uma redução de 1,59 log UFC/g e o hipoclorito de sódio demonstrou melhor eficácia na desinfecção com a concentração de $2,5 \%$ (T4) com uma redução de 2,27 log UFC/g (Figura 3). 
O hipoclorito de sódio é um agente bactericida que oxida as células microbianas provocando a morte do microrganismo, sendo amplamente utilizado na indústria de alimentos, pois o cloro tem um amplo espectro de atividade, uma vez que age de forma rápida e geralmente é mais barato (Møretrø et al., 2012). Embora os melhores resultados tenham sido obtidos no tratamento com hipoclorito de sódio, os demais tratamentos também apresentaram eficiência na redução de bactérias heterotróficas.

Segundo Trinetta et al. (2010), a lavagem e desinfecção dos vegetais antes do consumo, independentemente do sistema de cultivo utilizado, é a única medida tomada para reduzir o risco de contaminação dos vegetais folhosos como alface.

Esses resultados ressaltam que há necessidade de realizar a desinfecção de alfaces, pois a lavagem realizada apenas com água reduz uma quantidade muito pequena de microrganismos $\left(1,17 \log _{10} \mathrm{UFC} / \mathrm{g}\right)$, porém não é suficiente para manter a contaminação em níveis seguros, sendo essencial a aplicação de uma etapa de sanitização com agentes antimicrobianos (Maïworé et al., 2017).

Alguns trabalhos, como o de Horn (2014), ressaltam que um só tratamento, lavagem com água ou somente sanificante, não é suficiente para a eliminação de patógenos e que a lavagem sequencial é um importante método para eliminação de microrganismos, o que é observado neste trabalho também, ou seja, verificou-se que a lavagem somente com água foi o tratamento menos eficiente.

A análise estatística demonstrou que todos os tratamentos foram estatisticamente diferentes do controle (T0), mas os melhores resultados foram observados para o tratamento (T4) (Figura 3), no qual foi usado lavagem com água tratada corrente e posteriormente imersão em hipoclorito de sódio a 2,5\%, com cloro ativo de 200 ppm, por 30 minutos, seguido de enxague em água potável.

Nossos dados demonstraram que é importante utilizar métodos de lavagem e desinfecção antes do consumo de alfaces, tendo em vista que os melhores resultados de redução na contagem bacteriana foram observados nos tratamentos (T3 e T4) que utilizaram solução clorada para desinfecção.

\section{Conclusão}

Os resultados obtidos neste estudo permitem concluir que os consumidores de alfaces não realizam a higienização correta desse alimento, sendo que a maioria deles não tem conhecimento das metodologias adequadas para lavagem e desinfecção das hortaliças comercializadas in natura.

Além disso, os dados deste estudo também permitem concluir que a lavagem somente com água não é um método seguro para manter a qualidade microbiológica das alfaces, pois ainda restarão quantidades de bactérias nesses alimentos.

Desse modo, esses resultados são preocupantes, pois todas as amostras analisadas antes da higienização estavam contaminadas por bactérias heterotróficas, demonstrando a necessidade dos consumidores realizarem a correta lavagem e desinfecção desses alimentos antes do consumo.

Ainda, conclui-se que é necessário esclarecer a população da importância da higienização das verduras antes do consumo, tendo em vista que, apesar de o método mais eficaz ter sido aquele com o uso do hipoclorito de sódio na concentração de 200 ppm, ele é o menos utilizado pelos consumidores, em função do desconhecimento da eficácia ou por acreditar que isso é desnecessário.

\section{Referências}

Agência Nacional de Vigilância Sanitária - ANVISA. Gerência Geral de Alimentos. (2005). Cartilha sobre boas práticas para serviços de alimentação. Brasília: Ministério da Saúde. Recuperado em 13 de outubro de 2018, de http://portal.anvisa.gov.br/documents/33916/389979/Cartilha+Boas+Pr\%C3\%A1ticas+para+Servi\%C3\%A7os+de+Alimenta\%C3 \%A7\%C3\%A3o/d8671f20-2dfc-4071-b516-d59598701af0

Allen, J., Edberg, S. C., \& Reasoner, D. J. (2004). Heterotrophic plate count bacteria: What is their significance in drinking water? Food Microbiology, 92(3), 265-274. PMid:15145585. http://dx.doi.org/10.1016/j.ijfoodmicro.2003.08.017 
Alves, S. L. C.; Neves, M. C. P.; Costa, J. R. (2007, novembro). Avaliação da contaminação microbiológica de alface orgânica e convencional em diferentes pontos de comercialização. Seropédica, RJ.

Banach, J., Van Overbeek, L. S., Nierop Groot, M. N., Van der Zouwen, P. S., \& Van der Fels-Klerx, H. J. (2018). Efficacy of chlorine dioxide on Escherichia coli inactivation during pilot-scale fresh-cut lettuce processing. International Journal of Food Microbiology, 269, 128-136. PMid:29425860. http://dx.doi.org/10.1016/j.ijfoodmicro.2018.01.013

Bencardino, D., Vitali, L. A., \& Petrelli, D. (2018). Microbiological evaluation of ready-to-eat iceberg lettuce during shelf-life and effectiveness of household washing methods. Italian Journal of Food Safety, 7(1), 6913. PMid:29732325. http://dx.doi.org/10.4081/ijfs.2018.6913

Birmpa, A., Constantinou, P., Dedes, C., Bellou, M., Sazakli, E., Leotsinidis, M., \& Vantakaris, A. (2018). Antibacterial and antiviral effect of essential oils combined with non-thermal disinfection technologies for ready-to-eat Romaine lettuce. Journal of Nutrition Research and Technology, 1(1), 24-32. http://dx.doi.org/10.30881/jnfrt.00007

Bobco, S. E., Pierozan, M. K., Cansian, R. L., Oliveira, D., Pinheiro, T. L. F., \& Toniazzo, G. (2011). Condições higiênicas de alfaces (Lactuca sativa) comercializadas na cidade de Erechim - RS. Revista Alimentos e Nutrição, 22(2), 301-305.

Botella, S., Jiménez, A., \& Ferrin, M. (2018). Exploring microorganisms: Recent advances in applied microbiology. Boca Raton: BrownWalker Press.

Brasil. Agência Nacional de Vigilância Sanitária - ANVISA. (2004, 16 de setembro). Dispõe sobre regulamento técnico de boas práticas para serviços de alimentação (Resolução RDC n² 216, de 15 de setembro de 2004). Diário Oficial [da] República Federativa do Brasil, Brasília. Recuperado em 10 de setembro de 2018, de http://portal.anvisa.gov.br/documents/33916/388704/RESOLU\%25C3\%2587\%25C3\%25830-

RDC\%2BN\%2B216\%2BDE\%2B15\%2BDE\%2BSETEMBRO\%2BDE\%2B2004.pdf/23701496-925d-4d4d-99aa-9d479b316c4b.

Brasil. Ministério Da Agricultura, Pecuária E Abastecimento. Secretaria de Defesa Agropecuária (DISPOA). (2003, agosto 26). Instrução Normativa $n^{\circ} 62$, de 26 de agosto de 2003. Oficializa os Métodos Analíticos Oficiais para Análises Microbiológicas para Controle de Produtos de Origem Animal e Água. Diário Oficial [da] República Federativa do Brasil, Brasília, Seção 1.

Brasil. Ministério da Saúde. (2018). Surtos de doenças transmitidas por alimentos no Brasil. Brasília: Ministério da Saúde. Recuperado em 4 de setembro de 2018, de http://portalarquivos2.saude.gov.br/images/pdf/2018/janeiro/17/ApresentacaoSurtos-DTA-2018.pdf

Brasil. Ministério da Saúde. Agência Nacional de Vigilância Sanitária - ANVISA. (2001, 10 de janeiro). Dispõe sobre regulamento técnico sobre padrões microbiológicos em alimentos (Resolução RDC no 12, de 2 de janeiro de 2001). Recuperado em 20 de outubro de 2018, de http://pt.scribd.com/doc/47204244/rdc-no12-de-02-01-01

Ceuppens, S., Rodrigues, R. Q., Bartz, S., Tondo, E. C., \& Uyttendaele, M. (2014). Microbiological quality and safety assessment of lettuce production in Brazil. International Journal of Food Microbiology, 181, 67-76. PMid:24829142. http://dx.doi.org/10.1016/j.jifoodmicro.2014.04.025

de Andrade Bernal Fagiani, M., Natsumi Togawa, K., Reginato Martins, T., Toshiko Tashima, N., Leli Dillio, F., Henrique Nahas Chagas, P., \& Aparecida da Silva, M. (2017). Avaliação microbiológica e parasitológica de produtos minimamente processados no município de Presidente Prudente-SP. Colloquium Vitae, 9(2), 17-21. http://dx.doi.org/10.5747/cv.2017.v09.n2.v195

Elias, S. O., Decol, T., \& Tondo, E. C. (2018). Foodborne outbreaks in Brazil associated with fruits and vegetables: 2008 through 2014. Food Quality and Safety, 2(4), 173-181. http://dx.doi.org/10.1093/fqsafe/fyy022

Guerra, N. M. M., Otenio, M. H., Silva, M. E. Z., Guilermetti, M., Nakamura, C. V., Ueda-Nakamura, T. U., \& Dias Filho, B. P. (2006). Ocorrência de Pseudomonas aeruginosa em água potável. Acta Scientiarum. Biological Sciences, 28(1), 13-18. http://dx.doi.org/10.4025/actascibiolsci.v28i1.1053

Gündüz, G. T., Gönül, Ş. A., \& Karapınar, M. (2010). Efficacy of oregano oil in the inactivation of Salmonella typhimurium on lettuce. Food Control, 21(4), 513-517. http://dx.doi.org/10.1016/j.foodcont.2009.07.016

Holvoet, K., Sampers, I., Seynnaeve, M., \& Uyttendaele, M. (2014). Relationships among hygiene indicators and enteric pathogens in irrigation water, soil and lettuce and the impact of climatic conditions on contamination in the lettuce primary production. International Journal of Food Microbiology, 171, 21-31. PMid:24296259.

http://dx.doi.org/10.1016/j.jifoodmicro.2013.11.009

Horn, D. S. (2014). Higiene dos vegetais. Recuperado em 22 de novembro de 2017, de http://www.nutricaoeacao.com.br/higiene-dos-vegetais/

Jacxsens, L., Ibañez, I. C., Gómez-López, V. M., Fernandes, J. A., Allende, A., Uyttendaele, M., \& Huybrechts, I. (2015). Belgian and Spanish consumption data and consumer handling practices for fresh fruits and vegetables useful for further microbiological and chemical exposure assessment. Journal of Food Protection, 78(4), 784-795. PMid:25836406. http://dx.doi.org/10.4315/0362-028X.JFP-14-376

James, J., \& Ngarmsak, T. (2010). Processing of fresh cut tropical fruits and vegetables: A technical guide (pp. 102). Bangkok: Regional Office for Asia and the Pacific, Food and Agriculture Organization of the United Nations.

Jeena, M. I., Deepa, P., Mujeeb Rahiman, K. M., Shanthi, R. T., \& Hatha, A. A. (2006). Risk assessment of heterotrophic bacteria from bottled drinking water sold in Indian markets. International Journal of Hygiene and Environmental Health, 209(2), 191-196. PMid:16412688. http://dx.doi.org/10.1016/j.ijheh.2005.11.003

Maïworé, J., Baane, M. P., Tatsadjieu, N. L., Anyindong, J., Nkongho, E. A., Mbofung, C. M., \& Montet, D. (2017). Microbiological quality of lettuce (Lactuca sativa) consumed on the streets Maroua (Cameroon): Effect of disinfecting agents used by some vendors. International Journal of Microbiology Research, 9, 913-918. 
Conhecimento dos consumidores e eficiência dos métodos de lavagem e desinfecção de alface (Lactuca sativa) comercializada em supermercados em uma cidade do sul do Brasil

Rossi, E. M. et al.

Møretrø, T., Heir, E., Nesse, L. L., Vestby, L. K., \& Langsrud, S. (2012). Control of Salmonella in food related environments by chemical disinfection. Food Research International, 45(2), 532-544. http://dx.doi.org/10.1016/j.foodres.2011.02.002

Oliveira, A. B. A., Ritter, A. C., Tondo, E. C., \& Cardoso, M. I. (2012). Comparison of different washing and disinfection protocols used by food services in southern Brazil for lettuce (Lactuca sativa). Food and Nutrition Sciences, 3(1), 28-33. http://dx.doi.org/10.4236/fns.2012.31006

Osaili, T. M., Al-Nabulsi, A. A., \& Allah Krasneh, H. D. (2018). Food safety knowledge among foodservice staff at the universities in Jordan. Food Control, 89, 167-176. http://dx.doi.org/10.1016/j.foodcont.2018.02.011

Queiroz, C. C. Q. (2007). Água embotellada y su calidad bacteriológica. Tucson: Revista Água Latinoamérica, 38-39.

Schirmer, M., Picanço, N. F. M., \& Faria, R. A. P. G. (2019). Importance of training in ensuring the hygiene-sanitary quality of lettuce salads served in nursery schools. Brazilian Journal of Food Technology, 22, 1-9. http://dx.doi.org/10.1590/19816723.28218

Trinetta, V., Morgan, M. T., \& Linton, R. H. (2010). Use of high-concentration-shorttime chlorine dioxide gas treatments for the inactivation of Salmonella enterica spp. inoculated onto Roma tomatoes. Journal Food Microbiology, 27(8), 1009-1015. PMid:20832678. http://dx.doi.org/10.1016/j.fm.2010.06.009

Viacava, G., Goyeneche, R., Goñi, M. G., Roura, S. I., \& Aguero, M. V. (2018). Natural elicitors as pre-harvest treatments to improve the post-harvest quality of butterhead lettuce. Scientia Horticulturae, 228, 145-152.

http://dx.doi.org/10.1016/j.scienta.2017.10.018

Financiamento: Nenhum. 
Conhecimento dos consumidores e eficiência dos métodos de lavagem e desinfecção de alface (Lactuca sativa) comercializada em supermercados em uma cidade do sul do Brasil

Rossi, E. M. et al. 